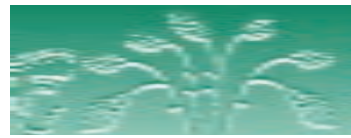

EDITORIAL/ EDITORIAL

DOI: http://dx.doi.org/10.12957/demetra.2015.16330

\title{
Autoria de artigos: questões para reflexão
}

\section{Authorship of articles: questions for reflection}

Um dos projetos nacionais de maior impacto nos anos recentes sobre a lida científica corresponde ao aumento do número de publicações, prioritariamente, em periódicos indexados em bases internacionais, como Journal Citation Reports / Thomson Reuters e SCImago Journal E Country Rank / Scopus/ Elsevier B.V. Para não ir muito longe, a simples manutenção do credenciamento de um docente / pesquisador em um programa de pós-graduação implica um mínimo de "produtos" publicados anualmente em periódicos indexados nessas bases.

Trata-se de fenômeno que tem trazido, efetivamente, ascensão do Brasil nos rankings mundiais de "produção" científica, ao mesmo tempo em que tem suscitado problemas de diversas ordens. No cenário concorrencial que impera nos quesitos captação de recursos e ocupação de posições (cargos) que conferem distinção aos que as alcançarem, podemos citar procedimentos através dos quais os agentes que operam no campo lançam mão em busca de capital, tanto material, quanto simbólico.

Partindo do reconhecimento relativo à importância de investimentos na geração de conhecimentos e na sua divulgação, trataremos aqui daquilo que diz respeito a uma parcela dos problemas acima aludidos e que dizem respeito à autoria de trabalhos submetidos aos periódicos científicos.

Nossa revista vem operando no sentido de valorizar abordagens oriundas dos diferentes campos científicos, numa perspectiva pluriepistemólogica. Isso significa lidar com várias culturas: tanto as que tradicionalmente valorizam os trabalhos de autor único, mais características das Ciências Humanas e Sociais, como as que são resultados de trabalhos de caráter biomédico realizados por equipes de laboratórios ou estudos epidemiológicos conduzidos igualmente por grupo(s) de pesquisa e, nestes casos, assinados por múltiplos autores. Predominam, contudo, as contribuições de cunho nutricional nas publicações em nossa revista, dada sua inserção no espaço social que guarda essa tônica. Em nossa lida editorial, temos notado, mesmo entre os trabalhos de caráter biomédico, o incremento cada vez mais intenso do número de autores por artigo. O crescimento do número de autores em trabalhos oriundos das Humanidades é também fenômeno recente entre os artigos submetidos à DEMETRA. 
Outros periódicos - como Cadernos de Saúde Pública, por exemplo - vêm assinalando, não sem certo desconforto, tais procedimentos. Diversas revistas vêm manifestando suas preocupações com tais situações e algumas - como a Revista de Nutrição - estabelecendo limites para o número de autores por artigo. Camargo Jr., Editor da Physis: Revista de Saúde Coletiva, assinala que "tem sido surpreendente receber manuscritos com um número de autores que se aproxima, ou às vezes ultrapassa, o número de sujeitos participantes na pesquisa que originou o artigo" e destaca "o fenômeno da multiplicação de autores, ao menos em parte dos casos devido à eufemisticamente denominada 'autoria honorária”. ${ }^{1}$

No plano internacional, em 2013, foi divulgada a San Francisco Declaration on Research Assessment (DORA), ${ }^{2}$ que alcançou a adesão de milhares de pesquisadores e centenas de organizações científicas. Este documento questiona, em profundidade, os processos de avaliação da produção científica que vem induzindo ao crescimento do número de publicações, incluindo o número de autores por artigo.

Em várias das áreas de avaliação institucionalizadas na Coordenação de Aperfeiçoamento de Pessoal de Nível Superior (CAPES), incluindo a assim denominada "Nutrição", periódicos brasileiros encontram-se em posição claramente secundarizada nos critérios de avaliação dos Programas de Pós-Graduação stricto sensu que a conformam. Ainda assim, os níveis de submissão de artigos têm crescido consideravelmente em nossa revista, o que acreditamos se deva, ao menos em parte, a essa indução ao publicar mais... e mais... e mais... que marca a produção de conhecimentos e formação de docentes e de pesquisadores, também no Brasil.

Observamos que, conforme o International Committee of Medical Journal Editors, a autoria é definida com base em contribuição substancial relacionada a: (1)concepção e projeto ou análise e interpretação dos dados; (2)redação do artigo ou revisão crítica relevante do conteúdo intelectual; (3)aprovação final da versão a ser publicada, condições que devem ser integralmente aceitas. Participações pontuais em coleta de dados ou outras contribuições de menor porte podem ser registradas como "Agradecimentos", diferenciando-se da autoria que implica na responsabilidade pelo registrado no texto final.

Shirley Donizete Prado Fabiana Bom Kraemer

1 Camargo JR., Kenneth R. de. Publicar ou perecer, ou perecer por publicar (em excesso)? Physis [online]. 2014, vol.24, n.2 [citado 2015-05-08], pp. 337-339. Disponível em: <http://www.scielo.br/scielo.php?script=sci_ arttext\&pid=S0103-73312014000200337\&lng=pt\&nrm=iso $>$. ISSN 0103-7331. http://dx.doi.org/10.1590/ S0103-73312014000200001

2 Acesso em 26 de novembro de 2014. Disponível em:http://am.ascb.org/dora/ 